\title{
Developing English Communication Skills through Project-Based Learning: The Case of ENSAM Engineering Students
}

\author{
Khalid Ben Kaddour
}

ENSAM (Ecole Nationale Supérieure d'Arts et Métiers), Moulay Ismail University Meknès, Morocco.

\begin{abstract}
This paper aims at examining closely English for Engineering Course and its impact on developing engineering students' communication skills. The Instruction used is Project-Based Learning $(P B L)$. Participants in the study $(N=66$, ages 20 to 25$)$ are $4^{\text {th }}$ year engineering students from the ENSAM engineering school (Ecole Nationale Supérieure d'Arts et Metiers) -Meknès. The objective behind this analytical report is testing the usefulness of this pedagogical approach on students learning. The main question raised is the extent to which the three communication skills addressed by the course, i.e., sequencing, analyzing, and illustrating, have been affected by this teaching methodology. The data have been analyzed empirically, and the findings reveal that PBL has a positive impact on developing these skills. General conclusions and pedagogical implications are presented.
\end{abstract}

Keywords- English for Specific Purposes, English for Engineering, Project-Based Learning, Communication Skills.

\section{INTRODUCTION}

This paper endeavours to shed light on the impact of PBL on ENSAM engineering students' communication skills, and the extent to which these skills, especially sequencing, analyzing, and illustrating, have been developed. It highlights the effectiveness of PBL in teaching English for engineering as it shows that effective teaching of English for vocational purposes is both a matter of content and method. The aim here is to bring to the fore the ways it is adopted and the results it has reached. This aim is demonstrated through a description of both the course content and the adopted learning.

\section{A BRIEF OVERVIEW OF ENGLISH IN} MOROCCAN ENGINEERING SCHOOLS

Moroccan engineering schools are not adopting a national curriculum for the English course contents as well as the teaching methodologies adopted. Each school has got its own syllabus. In the case of the ENSAM, General English is taught in preparatory cycle $\left(1^{\text {st }}\right.$ and $2^{\text {nd }}$ year $)$ while English for Specific Purposes is taught in engineering cycle $\left(3^{\text {rd }}, 4^{\text {th }}\right.$, and $5^{\text {th }}$ year). For the purpose of consistency, this paper attempts to focus on the $4^{\text {th }}$ year English for engineering course. It is an ESP course that seeks to develop engineering students' communication skills and facilitate the learning of English through technical subject matters.

At the level of methodology, most classes are carried out in a conventional way through comprehension exercises, grammar, and vocabulary teaching. Such a traditional teaching doesn't encourage students' participation in the learning process or even foster their autonomy; "it has been shown that PBL is a more effective education methodology compared to traditional pedagogies" (Noordin \& Nordin, 2018, p.475). Thus a shift of focus in the teaching methodology is needed, and using PBL becomes a must. PBL, as a student centred approach, helps engineering students become independent learners (Thomas, 2000; Westwood, 2008) since they should no longer be considered as passive recipients of knowledge. Instead, they are supposed to have reached a maturational stage where they can be involved in the language learning process purposefully. The argument is that, in view of the short amount of classroom instruction, $4^{\text {th }}$ year students can better their English if they are encouraged to carry out projects collaboratively and with a specific goal. The intent is to make students work outside the classroom. Therefore, working through projects is likely to make students work in group to achieve the tasks of their assigned project. Every project is centred on a communication skill, pushing students to collaborate to acquire the intended skill. The 
second and most important aspect in the course design process relates to the content of the course and its orientations. These features are addressed in the ensuing section.

\section{COURSE DESCRIPTION}

The teaching materials that the students are studying as part of their syllabus are mainly extracted from "English for Engineering”, (Mark Ibboston, 2008). This textbook provides issues that are part of the students' concern in their engineering studies. It is for engineers who need to use English in the workplace. It seeks to develop the communication skills and specialist English language knowledge of engineering professionals, enabling them to communicate more confidently with colleagues and customers. Among these communication skills, sequencing, comparing and analyzing skills are selected for the purpose of this paper.

The sequencing skill belongs to the third level of cognition, namely "Applying" (Anderson \& Krathwohl, 2001). It means that students are challenged to carry out or use a procedure in a given situation. To illustrate how to deal with the sequencing skill, "Exercise $3 \mathrm{~d}$ " is presented below.

d In pairs, do an environmental audit for the following applications and materials. Use the words and phrases in the box.

$\begin{array}{ll}\text { Application } & \text { Materials } \\ \text { electrical wires in vehicles } & \begin{array}{l}\text { copper and aluminium } \\ \text { bricks and softwood }\end{array}\end{array}$

as far as I know ... I I think so / I'd say so I'm (not) sure that's an important consideration that needs to be researched coated derived mixed recovered recycled

Fig.1: Exercise 3d concerning the sequencing skill

In this exercise, taken from the activities in Section1-Unit 2, students have to learn how to sequence the product phases, mainly the pre-use, in-use and post-use phases. They have to listen to an ecological adviser, Irina, talking to a group of engineers on a training course about environmentally friendly design, then apply the same procedure to do an environmental audit for some applications and materials, using the given phrases and words.

Secondly, the analyzing and illustrating skills belong to the fourth level of cognition, namely "Analyzing" (Anderson \& Krathwohl, 2001). It means that students are challenged to break materials into their constituent parts and detect how the parts relate to one another and to an overall structure or purpose. To exemplify how to deal with the illustrating and analyzing skills, "Exercise 2a" and "Exercise 6a" are presented below. "Exercise 2a" is taken from the activities in Section1-Unit1, dealing with the theme of "describing technical functions and applications". This section deals with language for describing what appliances do and what they are typically used for. The theme, global positioning system (GPS), represents a wellknown area of technology with a wide range of applications. The language covered is relevant to describing the purpose of any technological application, whether an individual component or a complex assembly in an electrical device, a mechanical assembly, a structure, a section of a production line, etc.

In "Exercise 2a", dealing with the illustrating skill, students have to analyze the given information before listening to the audio track to be able to describe the applications and function of the GPS.

2 a 1.1 Paula, a design engineer for a CPS manufacturer, is discussing product development with José, a senior manager new to the company. Listen to the conversation and complete the following notes.

- the primary application of CPS

- associated applications

Tracking systems for (2)

- more creative features

- not technical innovations Tracking systems for (3)
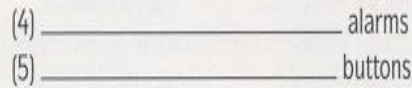

(6) the technology

Fig.2: Exercise 2 a concerning the illustrating skill

6 a You are going to give a talk on composites technology at a construction materials trade fair. In part of the talk, you focus on reinforced concrete as a well-known example of a composite material. Prepare your talk using words and phrases from this section and the following notes.

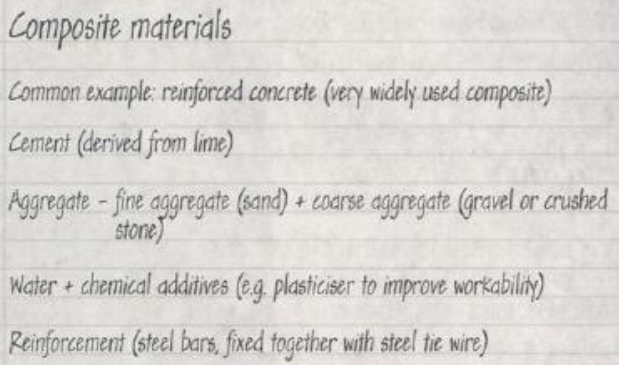

Fig.3: Exercise 6a concerning the analyzing skill

On the other hand, "Exercises $6 \mathrm{a}$ " is taken from the activities in Section2-Unit2, dealing with the theme of "categorizing materials". This section extends the topic of materials by looking at categories of engineering materials. The language is useful for understanding and describing the vast array of materials used in modern technology, such as conductors, insulators and semiconductors in electrical 
engineering, and composite materials and alloys in mechanical and civil engineering. In "Exercise 6a", which deals with the analyzing skill, students have to read the whole section, analyze its different activities, and collect the necessary information to give a talk on composites technology at a construction materials trade fair.

As exemplified above, the students deal with the chosen three communication skills as incorporated within different exercises, dealing with themes like mechanical engineering and engineering design in an authentic, relevant and motivating course. The students are dealing with the content of the chosen units conformingly to PBL features, through projects' development (Thomas, 2000; Curtis, 2002; Solomon 2003; Helle et al., 2006, Tynjala, \& Olkinuora, 2006). Altogether, the projects involved in the current course derive from the notion that learning is affected by the motivation raised by the targeted course (Pecore, 2013).

What are the various steps of the projects' development? How do these projects help engineering students develop their communication skills and foster their autonomy?

\section{THE STUDY}

The focus of this study is on the importance of PBL as a teaching method for engineering purposes. This methodology -as evidenced with its underlying principles and adopted with engineering students- is based on students' orientations and motivation to learn more about English for engineering. First, students are using English for engineering, which content is linked to their daily life; that's what makes it appealing for them (Good \& Brophy, 2002; Hmelo-Silver, 2004, Tan, Hung, \& Scardamalia, 2006). They see higher value in the authentic features that the projects incorporate. Second, they collaborate to develop their projects as team members. This group work allows them to engage and participate in their own learning and achieve the objective under the direction of the group members who have shared goals. For this reason, collaborative learning is seen as an essential feature of PBL (Stoller, 2006) where students are allowed to collaboratively investigate what is going on and construct what is being learned (Sidman-Taveau, 2005, Bédard, Lison, Dalle, Côté, \& Boutin, 2012). Third, they take responsibility and control over what, how, and when to learn to foster their autonomy; however, they are not fully autonomous as they are directed by the teacher within limits. In fact, the transition from a teacher-dependent traditional learning to an autonomous learning should be smooth; therefore, a controlled-like autonomous learning, where the teacher creates a balance, is opted for: s/he gives students the opportunity to make choices in their curriculum; meanwhile, s/he controls the amount of responsibility they have in making decisions. All of these three features are fully integrated in the engineering students' projects development. As a matter of fact, PBL promotes learning through projects. PBL is not only a learning method centred on projects but also the "projects are central, not peripheral to the curriculum" (Thomas, 2000 , p. 3). The teaching method is centred on the project while the activities are implemented as a central part of the curriculum. On the other hand, the central concepts developed in the learning program adopted in the classroom, namely mechanical and electrical engineering, are learned and discovered by the students through the project they are assigned. The development of the projects makes of PBL an ongoing process through which students shape their projects and understand what is expected of them with support from their teacher. What are the steps of a project development? How do these projects help engineering students develop their communication skills and foster their autonomy?

\subsection{Steps of project development}

As described below, the development of the projects goes through four major steps: starting the project, developing the project, reporting the project, and assessing the project (Markham, et al., 2003; Tsiplakides, Fragoulis, \& Keramida, 2011; Antic \& Spacic, 2012). In the beginning, each group has the responsibility to design their own project development. This development consists of establishing the project's outline, planning the method of development, and sharing responsibilities among the group members. At this stage, some scaffolding is necessary as the teacher hands out a CD to each group, containing a detailed description of what to do. Students, then, start collecting as much information as possible to deal with the assigned project and answer the different driving questions. They select relevant information to the project and organize their data in a well-structured text to build up a well-designed presentation. This latter constitutes the project's end-product. In this presentation, students should summarize the tasks they worked on at home to their classmates, focusing on the new vocabulary and language expressions they have discovered. Its content introduces the communication skills on which the textbook section focuses. Then, students report to the class what they have achieved in their project development through their presentations, using presentation software such as PowerPoint. The time allotted to the presentation delivery is fifteen minutes, in which students have to show mastery of the verbal and non verbal communication techniques of good delivery. Different group members should adequately 
use visual aids to accompany their delivery. This endproduct gives students the opportunity to take pride in their work and show their presentation delivery skills that are core skills for both professional and academic engineers as they are supposed to make effective presentations to clients in meetings and at conferences (Mutsumi IIJIMA et al, 2010). Finally, students' presentations are videotaped then projected for the sake of teacher and students' feedback. This kind of feedback leads us to the last step of project development, which is the assessment of the end-product. It is a performance-based assessment as it refers to students' requirement to actively accomplish complex and significant tasks while making use of their prior knowledge, recent learning, and relevant skills to solve realistic or authentic problems. Assessing students this way aims at evaluating students' process of learning (SidmanTaveau \& Milner-Bolotin, 2001) as well as their project development skills (Blumenfeld, et al., 1991). This variety of assessment procedures comprises the individual student's assessment (self-assessment), the group assessment (peer-assessment), the teacher's assessment (co-assessment), and the portfolio assessment.

First, the self-assessment is an opportunity for students to evaluate their own work and thus become active, responsible, and motivated to participate in their knowledge acquisition (Bergh, et al., 2006). As an example, while visualizing their videotaped presentations, students become aware of their own delivery flaws and strengths; they have, then, a chance to improve their delivery techniques for further presentations.

Second, peer-assessment is an opportunity for students to assess their peers' projects and learning processes, providing them with continuous feedback and offering suggestions for improvement or giving support (Wilson, 2001). In this way, students are not only developing the important skill of giving constructive feedback (O'Farrell, 2005) but also increase confidence in assessing the quality of their own work (Wilson, 2001).

Third, co-assessment is used as a means for teachers to assist and supervise the learning process among students (McGrath, 2003; Solomon, 2003; Buchanan, 2004). It is also used as an instrument to provide feedback for students and allow them to make revisions through means of peer criticism and group evaluations (Larmer \& Mergendoller, 2010). Every presentation is videotaped, projected and visualized by the students during the course sessions, which offers both the teacher and the students the scope to give feedback, focusing on the good technical side of each delivery and raising some of the flaws that should be adjusted. It is assumed in the study that this received feedback on the progress of the project, the accomplished improvements, and the achieved performance enables students to evaluate their constructed knowledge and allows them to discover to what extent they have succeeded in applying and presenting what they have learned.

Finally, the portfolio assessment is achieved through individual reports submitted by the participants. In these portfolios, students document and keep track of their projects' development and select critical pieces to construct their end products. From these selected pieces, a report is submitted. This report is e-mailed to the teacher by each group of students. It describes the experience the group went through while dealing with the authentic features that the project incorporates. It gives students the possibility to indirectly voice their opinion about their understanding of the content and allows them to relate the different developing stages of the project, explaining the encountered problems and ways to solve them. Therefore, in this report, students firstly inform the teacher about what they have learned concerning language, content knowledge, and the teaching method. Secondly, they give an account of the difficulties they have encountered concerning language, content knowledge, and the teaching method. And finally, they communicate their suggestions concerning language, content knowledge, and the teaching method. This report can increase students' self-efficacy and writing skills, involve their empowerment and dialogue, promote their achievement, develop their metacognitive awareness, and strengthen the partnership with their teacher (Devlin-Scherer, 2005; Pereira de Eca, 2005). The use of this evaluative procedure is made to include all the ingredient of the learning operation.

\subsection{Impact of projects on students' autonomy and communication skills}

Autonomous learning is inherent in the development of the students' assigned projects and allows them to construct their own learning. The results of the present study confirmed that being autonomous was a productive way towards successful projects accomplishment. A favourable learning environment should offer the "ability to devise strategies, such as those for learning languages, where learning is enhanced by peer interaction and according to principles of learner autonomy" (Marsh, 2012, p.411). Before being exposed to PBL, the engineering students were passive and teacher-dependent as they were coming from a traditional educational background. Knowing that "the practice of PBL seeks to shift the locus of control from teachers to students" (Levitt, McKeage, \& Rangachari, 2013, p.187), it was not obvious for these students to accommodate to PBL's autonomous learning 
and instantly accept their new roles as active learners. However, owing the teacher's guidance throughout the whole projects development process, they could progressively transit from being teacher-dependent towards being autonomous learners.

Students have also developed their communication skills at the level of the projects' development. As pointed out before, PBL is a powerful and motivating teaching method to develop learners' second and/or foreign languages through projects where learning occurs in the context of generating projects and developing communication skills (Hutchinson, 1993; Ribe \& Vidal, 1993; Florez, 1998; Maley, 2002; McGrath, 2002-2003, Chen \& Yang, 2019). In the present study, the process of learning the sequencing, analyzing and illustrating communication skills was carried through the projects these students were assigned, dealing with engineering English. Thus, they have shown interest in working on projects whose activities are relevant to their lives. Moreover, they were motivated to learn and develop their communication skills, obtaining good results at the final exam. Concerning the sequencing and analyzing skills, and according to students' scores, the sixty six students can be grouped into four categories, going from the highest to the lowest grades: The first category $\mathrm{C} 1$ contains eight students who have a grade less than $12 / 20$. The second category $\mathrm{C} 2$ contains twelve students who have a grade between $12 / 20$ and 14/20. The third category C3 contains twenty eight students who have a grade between $14 / 20$ and 16/20. The final category $\mathrm{C} 4$ contains eighteen students who have a grade between 16/20 and 20/20. The bar-graph and piechart in figure 4 (below) illustrate the good grades most of the students scored in relation to the sequencing and analyzing skills. In fact, the majority of students (70\%) achieved scores higher than 14/20. They have shown that they didn't find difficulties to deal with the "sequencing and analyzing skills" tasks. On the other hand, the failure of $12 \%$ of the students to achieve the average grade of $12 / 20$ might be due to other problems such as language deficiencies as well as lack of familiarity with these skills. The majority of them explained in their final report that their major problem sprang from lack of the necessary technical vocabulary, showing that ability to sequence and analyze a set of materials needs both linguistic and content knowledge as well as effective metagognitive strategies. In short, the results concerning these skills show that this category of students couldn't carry out sequencing many engineering techniques at a time, especially that this skill demands a prerequisite knowledge of some engineering techniques in English. This task is even made more complex by the fact that it demands a set of specific vocabulary items.

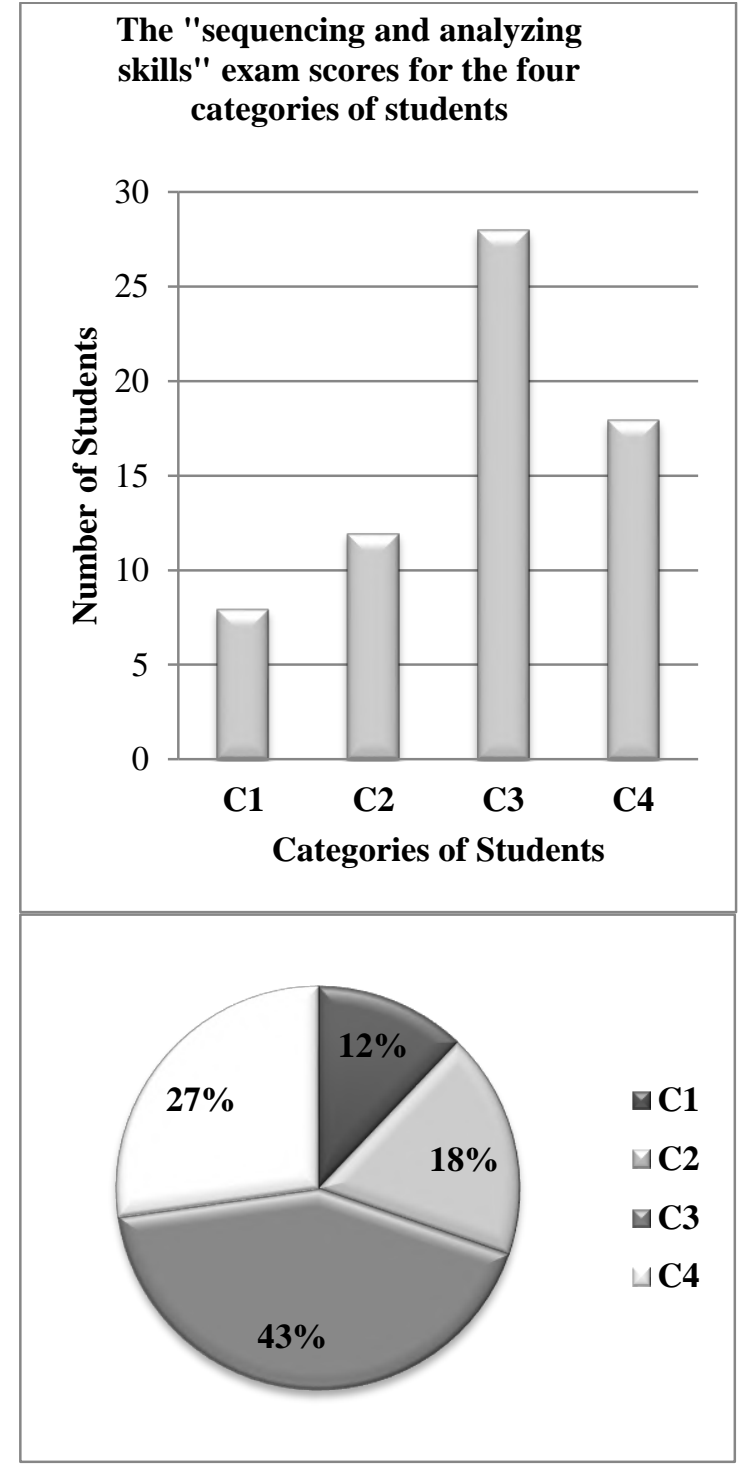

Fig.4: Bar graph and pie chart showing exams scores concerning the sequencing and analyzing skills for the four categories of students

ENSAM Engineering students have significantly developed their "sequencing and analyzing skills" at the end of the semester. The process of learning the "sequencing and analyzing skills" has been carried through the projects these students were assigned. Through collaboration, they had an opportunity to use the target language extensively both inside and outside the classroom, developing their "critical thinking, investigative skill building, motivation, and communicative competence" (Stoller, 2006, p. 31). In fact, through PBL, students' collaboration resulted in "a sharing of authority and acceptance of responsibility among group members for the groups actions" (Panitz, 1996, p.3), and in a spontaneous process of help and give support (Davidson, 
1994). Thus they succeeded in improving their "sequencing and analyzing skills" as they have been able to take up the challenge of carrying out the procedure of sequencing many techniques, such as manufacturing techniques and environmental audits. Also they have demonstrated that they were able to break materials into their constituent parts and detect how the parts relate to one another and to an overall structure or purpose, clarifying existing information by examining parts and relationships. For that, they were able to analyze sets of given texts as well as audio tracks in which they could identify materials' attributes and components by specifying their properties and by recognizing ways these properties were related.

Concerning the illustrating skill, and according to students' scores, they can be grouped into four categories, going from the highest to the lowest grades: The first category $\mathrm{C} 1$ contains twenty eight students who have a grade less than $12 / 20$. The second category C2 contains five students who have a grade between $12 / 20$ and 14/20. The third category C3 contains four students who have a grade between 14/20 and $16 / 20$. The final category $\mathrm{C} 4$ contains twenty nine students who have a grade between $16 / 20$ and 20/20. The bar-graph and pie-chart in Figure 5 (below) illustrate the good grades most of the students scored in relation to the illustrating skill for these four categories. Indeed, students have significantly developed their "illustrating skill" at the end of the semester. More than half of the students were able to adequately illustrate basic engineering techniques, showing through simple examples their understanding of how these techniques work and their ability to choose the right engineering jargon to describe them. However, it is noteworthy to indicate that $42 \%$ of the students couldn't score the average grade of $12 / 20$. This might have been due to language problems as well as their inability to deal with this skill. The majority of them explained in their final report that their major problem wasn't related to $\mathrm{PBL}$ or the process of developing their projects but sprang mainly from the necessary technical vocabulary. The difficulty to illustrate materials in English might have affected their ability to illustrate engineering techniques, showing that this ability needs both linguistic and content knowledge. In fact, the achievement of this skill requires a deep understanding and knowledge of the information related to these techniques, using simple and familiar examples to explain difficult concepts. This failure might have also been due to their lack of training into this type of activity or some other factors beyond the search of the present study.

Similarly to the sequencing and analyzing skills, developing projects collaboratively has had a beneficial impact on the final exam scores concerning the illustrating skill.

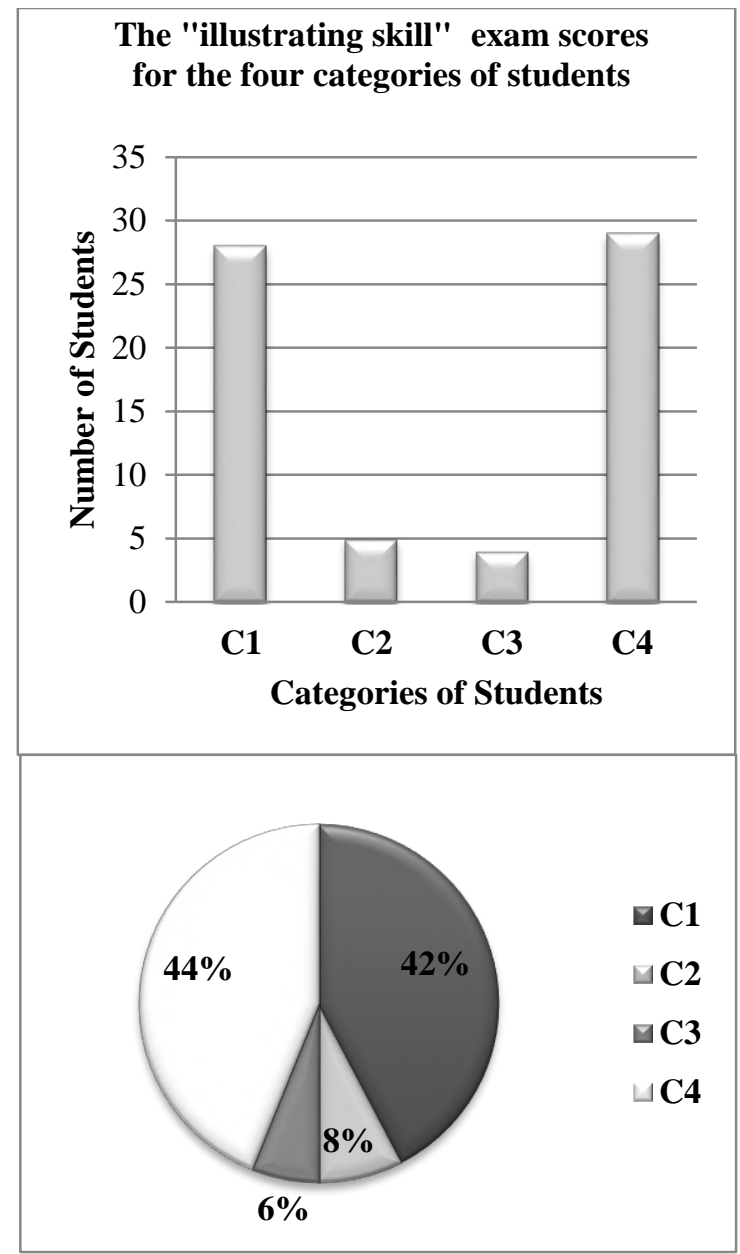

Fig.5: Bar graph and pie chart showing exams scores concerning the illustrating skill for the four categories of students

All in all, the features of PBL, mainly authentic, autonomous and collaborative learning, have helped students develop better communication skills. PBL indeed proves to be a powerful and motivating teaching method to foster students' autonomy and develop their communication skills (Chen \& Yang, 2019). These benefits have been achieved through collaboration and extensive use of the target language both inside and outside the classroom.

\section{CONCLUSION}

This analytical report shows that PBL is a useful methodology that fosters ENSAM engineering students' communication skills development and boosts their autonomy. Before being exposed to PBL, these students were passive and teacher-dependent as they came from a 
traditional educational background. It was not obvious for them to accommodate to PBL's autonomous learning and instantly accept their new roles as active learners. There is no doubt that "as a result of using PBL, students have been able to get a better understanding of the learning outcomes of the course" (Noordin \& Nordin, 2018, p.483). Students have shown perspicacious insight into the English for engineering course content; therefore, they have succeeded in developing the targeted communication skills by means of each weekly classroom project's end-product delivery that was followed by teacher and peers constructive feedback. This strategy of varied project assessment procedures has revealed to be fruitful, helping students not only develop their communication skills but also increase confidence in assessing the features of their own performance and the quality of their achievement.

\section{REFERENCES}

[1] Anderson, L. W., \& Krathwohl, D. R. (Eds.). (2001). A taxonomy for learning, teaching and assessing: revision of Bloom's taxonomy of educational objectives. New York: Longman.

[2] Antic, D., \& Spacic, A. (2012). Project-based learning in English for Medecine. Acta Medica Medianae, 51(2), 50-55.

[3] Bédard, D., Lison, C., Dalle, D., Côté, D., \& Boutin, N. (2012). Problem-based and Project-based Learning in Engineering and Medicine: Determinants of Students' Engagement and Persistance. Interdisciplinary Journal of Problem-based Learning, 6(2), 7-30

[4] Bergh, V. V. D., Mortelmans, D., Spooren, P., Petegem, P. V., Gijbels, D., \& Vanthournout, G. (2006). New assessment modes within project-based education - The stakeholders. Studies in educational evaluation, 32, 345-368

[5] Blumenfeld, P. C., Soloway, E., Marx, R. W., Krajcik, J. S., Guzdial, M., \& Palincsar, A. (1991). Motivating projectbased learning: Sustaining the doing, supporting the learning. Educational Psychologist, 26(3/4), 369-398.

[6] Buchanan, E. A. (2004). Online assessment in higher education: Strategies to systematically evaluate student learning. In C. Howard; K. Schenk \& R. Discenza (Eds.), Distance learning and university effectiveness: Changing educational paradigms for online learning (pp. 163-176). Hershey, PA: IGI.

[7] Chen, C. H., \& Yang, Y. C. (2019). Revisiting the effects of project-based learning on students' academic achievement: A meta-analysis investigating moderators. Educational Research Review, 26, 71-81.

[8] Devlin-Scherer, R. (2005). Teaching for real learning: Classroom applications, grades 4-12 (pp.23-87). Lanham, MD: Rowman \& Littlefield Publishing Group.

[9] Good, T. L., \& Brophy, J. E. (2002). Looking in classrooms. Boston: Allyn and Bacon.
[10] Helle, L., Tynjala, P., \& Olkinuora, E. (2006). Project-based learning in post-secondary education-theory, practice and rubber sling shots. Higher Education, 51(2), 287-314.

[11] Hmelo-Silver, C. E. (2004). Problem-based learning: What and how do students learn? Journal Educational Psychology Review, 16(3).

[12] Ibboston, M. (2008). English for engineering. Cambridge: Cambridge University Press.

[13] Iijima, M., Murrow, P. J., and Hattori, M. (2010). Teaching English Language Skills to Students of Engineering in Japan. IFAC Proceedings Volumes, 42(24), 268-271.

[14] Larmer, J. \& Mergendoller, J. (2010). 7 essentials for project-based learning. Educational Leadership, September 2010, 34-37.

[15] Levitt, S., McKeage, A., and Rangachari, P. K. (2013). Drugs, Devices, and Desires: A Problem-based Learning Course in the History of Medicine. Interdisciplinary Journal of Problem-Based Learning, 7(1), 186-202. https://doi.org/10.7771/1541-5015.1324

[16] Markham, T., Mergendoller, J., Larmer, J., \& Ravitz, J. (2003). Project-based learning handbook. Canada: Buck Institute for Education.

[17] Marsh, D. (2012). Content and language integrated learning (CLIL): a development trajectory. Spain: University of Cordoba

[18] McGrath, D. (2003). Designing to learn. Learning \& Leading with Technology, 30(6), 50-53.

[19] Noordin, M. K., \& Nordin, M. S. (2018). Project-Based Learning (PjBL) Framework in Developing Non-Technical Skills for Engineering Students. Advanced Science Letters, 24(6), 4515-4518.

[20] O'Farrell, C. (2005). Enhancing student learning through assessment. Retrieved from http://www.tcd.ie/CAPSL/academic_practice/worddocs/asse ssment_toolkit.doc

[21] Panitz, T. (1996). A definition of collaborative vs cooperative learning. Retrieved from http://www.londonmet.ac.uk/deliberations/collaborativelearning/panitz-

[22] Pecore, J. L. (2013). Beyond beliefs: Teachers adapting problem-based learning to preexisting systems of practice. Interdisciplinary Journal of Problem-based Learning, 7(2), 127.

[23] Pereira de Eca, M. T. (2005). Using portfolios for external assessment: An experiment in Portugal. International Journal of Art \& Design Education, 24(2), 209-218.

[24] Sidman-Taveau, R. L. (2005). Computer-assisted project based learning in second language: Case studies in adult ESL. PhD Thesis. The University of Texas at Austin.

[25] Solomon, G. (2003). Project-based learning: A primer. $T \& L$ Magazine, 23(6).

[26] Sthapornnanon, N., Sakulbumrungsil, R., The eraroungchaisri, A., \& Watcharadamrongkun, S. (2009). Social constructivist learning environment in an online professional practice course. American Journal of Pharmaceutical Education, 73(1), Article 10. 
[27] Stoller, F. (2006). Establishing a theoretical foundation for project-based learning in second and foreign language contexts. In G. H. Beckett \& P. C. Miller (Eds.), ProjectBased Second and Foreign Language Education: Past, Present, and Future (pp. 19-40). USA: Information Age Publishing.

[28] Tan, S. C., Hung, D., \& Scardamalia, M. (2006). Education in the knowledge age - Engaging learners through knowledge building. In D. Hung \& M. S. Khine (Eds.), Engaged learning with emergin technologies. Dordrecht: Springer.

[29] Thomas, J. W. (2000). A review of research on PBL. http://www.bobpearlman.org/BestPractices/PBL Research.pdf

[30] Tsiplakides, I., Fragoulis, J., \& Keramida, A. (2011). Content-based instruction in the teaching of English as a foreign language. Review of European Studies, 3(1), 115-121

[31] Westwood, P. (2008). What teachers need to know about teaching methods. Camberwell, Vic. : ACER Press.

[32] Wilson, S. Y., \& Liepolt, W. (2004). What is constructivism? Retrieved from http://www.thirteen.org/edonline/concept2class/constructivis m/index.html. 